\title{
Para além das grades e punições: uma revisão sistemática sobre a saúde penitenciária
}

\author{
Beyond bars and punishments: a systematic review of prison health
}

Swyanne Macêdo Gois ${ }^{1}$

Hudson Pires de Oliveira Santos Junior ${ }^{2}$

Maria de Fátima de Araújo Silveira ${ }^{1}$

Mércia Maria de Paiva Gaudêncio ${ }^{1}$

${ }^{1}$ Conselho Universitário, Universidade Estadual da Paraíba. Av. das Baraúnas 351, Bodocongó. 58109-753 Campina Grande PB. fatimasilveir@uol.com.br ${ }^{2}$ Universidade de São Paulo.

\begin{abstract}
A systematic review of scientific production on Prison Health was conducted, seeking to verify how the subject matter has been dealt with, establishing which is the most exploited focus and identifying possible gaps. The search was carried out in the Virtual Health Library. 1160 articles were located: 1104 on MEDLINE, 19 on LILACS and 37 on SciELO, published from 1993 to 2010. As MEDLINE and LILACS do not show the entire articles, the places, dates and languages of the texts were charted. In-depth analysis was restricted to works which were shown in their entirety and free of charge hosted on SciELO. It revealed that scientific production is present all over the world with a predominantly quantitative approach. It focuses on identifying the socio-demographic profile and health conditions of prisoners, the incidence of tuberculosis, Human Immunodeficiency and Hepatitis $C$ virus infections. There is a predominance of studies carried out with male prisoners, in comparison with the female sex. It is clear that prisoner health is a public health problem on the rise, which demands research that can orient health policies and strategies.
\end{abstract}

Key words Delivery of healthcare, Primary healthcare, Prisons, Prisoners
Resumo Procedeu-se a uma revisão sistemática acerca das produções científicas sobre Saúde Penitenciária, objetivando verificar como a temática vem sendo abordada, identificar qual o foco mais explorado e apontar possíveis lacunas. A busca foi realizada na Biblioteca Virtual de Saúde. Foram localizados 1160 artigos: 1104 na Medline; 19 na Lilacs e 37 na SciELO, publicados no período de 1993 a 2010. Como as bases de dados da Medline e da Lilacs não disponibilizam os artigos na integra, foram mapeados os locais, as datas e o idioma de publicação dos textos. O aprofundamento analítico delimitou-se aos trabalhos cujos textos estavam na integra e disponibilizados gratuitamente, hospedados na SciELO. Evidenciouse que a produção científica está presente nos cinco continentes do mundo, apresentando predominância da abordagem quantitativa, com foco na identificação do perfil sociodemográfico e das condições de saúde dos encarcerados: incidência de tuberculose, de infecção pelo Vírus da Imunodeficiência Humana e pelo Virus da Hepatite C. Há uma predominância de estudos realizados com detentos do sexo masculino, em comparação ao sexo feminino. Percebe-se que a saúde dos detentos é um problema de saúde pública emergente, que demanda pesquisas que possam vir a orientar politicas e estratégias de saúde.

Palavras-chave Assistência à saúde, Atenção primária à saúde, Prisões, Prisioneiros 


\section{Introdução}

Para efeitos conceituais, esse trabalho se ancora no conceito de saúde afirmado pela $8^{a}$ Conferência Nacional de Saúde, que entende que a saúde é resultante das condições de alimentação, habitação, educação, renda, meio ambiente, trabalho, transporte, emprego, lazer, liberdade, acesso e posse de terra e acesso a serviços de saúde. E que o direito à saúde significa a garantia, pelo estado, de condições dignas de vida e de acesso universal e igualitário às ações e serviços de promoção, proteção e recuperação da saúde, em todos os seus níveis, a todos os habitantes do território nacional ${ }^{1}$.

Nesse contexto, a Lei de Execução Penal brasileira $^{2}$, no título II, capítulo II, art. 14, dispõe que a atenção à saúde do preso e do internado, de caráter preventivo e curativo, deve compreender atendimento médico, farmacêutico e odontológico; e quando o estabelecimento penal não estiver aparelhado para prover tal assistência, esta será prestada em outro local, mediante autorização da direção da instituição.

Porém, as condições limites de vida e saúde da população que se encontra em unidades prisionais, levam-nos a refletir que embora a legislação vise a prevenir o crime e a garantir o retorno à convivência social, as precárias condições de confinamento tornam-se um dos empecilhos a esta meta, bem como impossibilitam o acesso das pessoas presas à saúde de forma integral e efetiva.

Embora existam Leis e Tratados nacionais e internacionais que buscam contribuir para uma melhor assistência à população encarcerada, é notória a falta de operacionalização, gerando grande preocupação em relação à situação em que se encontram essas pessoas, refletindo-se em práticas de violência e descaso com a saúde física e psíquica ${ }^{3}$.

Buscando responder a tal problemática, em setembro de 2003, por meio da Portaria Interministerial no 1.777, do Ministério da Justiça e do Ministério da Saúde ${ }^{4}$, foi instituído o Plano Nacional de Saúde no Sistema Penitenciário, desenvolvido dentro de uma lógica de atenção à saúde fundamentada nos princípios do Sistema Único de Saúde (SUS), cujo objetivo é promover atenção integral à população confinada em unidades prisionais masculinas e femininas, inclusive nas psiquiátricas.

Os princípios que fundamentam esse Plano no Sistema Penitenciário são pautados na ética, justiça, cidadania, direitos humanos, participa- ção, equidade, qualidade e transparência. E tem como diretrizes estratégicas ${ }^{5}$ :

- Prestar assistência integral resolutiva, contínua e de boa qualidade às necessidades de saúde da população penitenciária;

- Contribuir para o controle e/ou redução dos agravos mais frequentes que acometem a população penitenciária;

- Definir e implementar ações e serviços consoantes com os princípios e diretrizes do SUS;

. Proporcionar o estabelecimento de parcerias por meio do desenvolvimento de ações intersetoriais;

. Contribuir para a democratização do conhecimento do processo saúde/doença, da organização dos serviços e da produção social da saúde;

- Provocar o reconhecimento da saúde como um direito da cidadania;

. Estimular o efetivo exercício do controle social.

A homologação do Plano Nacional de Saúde no Sistema Penitenciário representa um avanço para o País, pois, pela primeira vez, a população das unidades prisionais é objeto de uma política de saúde específica, que regulamenta o acesso a ações e serviços que visam reduzir os agravos e danos provocados pelas condições de confinamento em que se encontram.

No contexto internacional, Walmsley ${ }^{6}$ considera os serviços de saúde prisional, como parte dos sistemas de saúde que contribuem para o bem-estar social de toda a sociedade. Enfatiza ainda, que as pessoas marginalizadas devido ao encarceramento não devem ser esquecidas pelo sistema de saúde.

Em face desta problemática, a OMS iniciou o Projeto de Saúde no Sistema Prisional em 1995. O objetivo deste projeto é promover a saúde pública e cuidados nas prisões, bem como facilitar as ligações entre a saúde no sistema prisional e os sistemas de saúde pública, tanto a nível nacional quanto internacional. Oferecem, ainda, consultoria especializada para os seus Estados-Membros no desenvolvimento do sistema de saúde nas prisões e de uma série de questões técnicas relativas às doenças transmissíveis, especialmente a tuberculose, a Síndrome da Imunodeficiência Adquirida (SIDA), a hepatite e o uso de drogas ilícitas, incluindo a terapia de substituição/ redução de danos e de saúde mental ${ }^{6}$.

Uma das atividades do Projeto de Saúde no Sistema Prisional inclui uma série de publicações sobre questões específicas de saúde. A publicação mais recente, e considerada de grande importância, é o Guia Saúde nas Prisões ${ }^{7}$ na qual são abor- 
dados muitos temas sobre a saúde dos presos. A equipe responsável pelo Projeto publicou também a Declaração de Moscou, enfatizando que a saúde no sistema prisional e serviços públicos de saúde devem trabalhar em conjunto ${ }^{6}$.

Conforme o Guia Saúde nas Prisões, várias normas internacionais definem a qualidade dos cuidados de saúde que deve ser provida aos prisioneiros. O princípio no qual os presos não devem sair da prisão em pior situação do que quando entraram, é reforçado pela Recomendação No 7 do Comitê de Ministros do Conselho da Europa (1998) e pelo Comitê Europeu para a Prevenção da Tortura e Penas ou Tratamentos Cruéis, Desumanos ou Degradantes $(\mathrm{CPT})^{7}$.

Diante da contextualização, o presente estudo propõe apresentar uma revisão sistemática dos trabalhos publicados sobre saúde penitenciária, com o objetivo de verificar como a temática vem sendo abordada, na busca de contribuir com a consolidação de dados sobre o tema; subsidiar futuras investigações e descrever o atual estado da arte a respeito do assunto.

\section{Metodologia}

Trata-se de um estudo de revisão sistemática que é uma forma de síntese das informações disponíveis em dado momento, sobre um problema específico, de forma objetiva e reproduzível, por meio de método científico. A revisão sistemática difere da revisão tradicional, uma vez que busca superar possíveis vieses em todas as etapas, seguindo um método rigoroso de busca e de seleção de pesquisas; avaliação da relevância e da validade das encontradas; coleta, síntese e interpretação dos seus dados ${ }^{8}$.

Assim, adotou-se um conjunto ordenado de critérios que determinam a cientificidade de uma revisão sistemática de literatura, iniciando pela construção de um protocolo, cuja função foi garantir o rigor do processo de pesquisa. Para isso, o protocolo dispunha dos seguintes componentes: pergunta de revisão, critérios de inclusão e exclusão, estratégias para a busca do universo de pesquisas, orientação para a seleção do material, análise e síntese dos dados, conforme apresentado a seguir.

Definição da pergunta: Como o tema Saúde Penitenciária vem sendo abordado em artigos científicos?

A busca dos estudos foi realizada de forma ampla através da Biblioteca Virtual em Saúde (BVS), que hospeda bases de dados reconheci- das. A busca foi realizada a partir dos descritores "Saúde", "Prisões", "Prisioneiros" e "Presídios". No cruzamento das palavras foi adotada a expressão booleana: “AND” (inserção de duas ou mais palavras). Cujo resultado obtido conduziu a pesquisa às bases de dados: Medical Literature Analysis and Retrieval System Online (Medline), Literatura Latino-Americana e do Caribe em Ciências da Saúde (Lilacs) e Scientific Eletronic Library Online (SciELO).

Os critérios de inclusão foram: artigos originais; disponibilizados online; nos idiomas português, inglês ou espanhol; com definição do método, cenário do estudo, população estudada, apresentação consistente dos resultados encontrados.

Os critérios de exclusão foram: qualquer fator que não atendesse aos critérios de inclusão; estudos que apresentassem erros sistemáticos; estudos de revisão, relatos de caso ou comunicação; além de ambiguidade e apresentação insuficiente dos resultados.

A coleta dos dados foi norteada em três momentos distintos e complementares, a saber:

a) Teste de relevância preliminar: que teve o objetivo de refinar a seleção inicial de artigos. Essa fase se procedeu com um questionário de perguntas claras que gerava reposta afirmativa ou negativa, criadas a partir dos critérios de inclusão e exclusão. Foi operacionalizada por um dos pesquisadores, o qual removeu apenas as referências que foram obvias à exclusão;

b) Teste de relevância II: foi operacionalizado pelo pesquisador que fez o teste de relevância preliminar, juntamente com o segundo pesquisador, que analisaram, de forma independente, os artigos que passaram pelo primeiro Teste, e só após finalizarem a análise se reuniram e discutiram os artigos que passariam para a fase seguinte. Tal postura foi tomada com a finalidade de verificar a objetividade do método. Ressalta-se que o teste de relevância II foi aplicado em estudos na íntegra, verificando através de perguntas claras os seguintes fatores: se tinham relação direta com a questão estudada (saúde penitenciária), se a metodologia estava suficientemente descrita e adequada ao alcance dos objetivos propostos, e se os resultados estavam compatíveis com a metodologia empregada.

c) Teste de relevância final: norteado a partir dos resultados anteriores. Aqui foram extraídas, por toda a equipe de pesquisadores, informações detalhadas de cada pesquisa, tais como: dados que caracteriza a autoria, referência bibliográfica, tipo de pesquisa, rigor metodológico, cenário do 
estudo, tamanho da amostra, evidência dos resultados encontrados e sua credibilidade.

O processo de síntese dos dados foi realizado por meio de uma análise descritiva dos estudos selecionados após a fase anterior, sendo o produto final da análise apresentado de forma narrativa.

\section{Resultados e discussões}

\section{Categorização das produções localizadas}

$\mathrm{Na}$ pesquisa na Biblioteca Virtual de Saúde (BVS), no ícone via descritores DeCS/MeSH, com a utilização das palavras-chave "Saúde AND Prisões", foi observado que o resultado da procura na opção "busca por todos os descritores", foram encontrados 293 estudos na Medline; 9 na Lilacs e 12 na SciELO. Utilizando-se as palavraschave "Saúde AND Prisioneiros", encontrou-se 499 estudos na Medline; 11 na Lilacs e 15 na SciELO. E por fim, utilizando-se as palavras-chave "Saúde AND Presídios", encontrou-se 399 estudos na Medline; 6 na Lilacs e 10 na SciELO.

Após um refinamento, no qual se excluíram os trabalhos que se repetiam nas três combinações de descritores, encontrou-se 1160 estudos, sendo: 1104 na Medline; 19 na Lilacs e 37 na SciELO, sendo encaminhados para análise através do Teste de Relevância Preliminar.

Como as bases de dados da Medline e Lilacs não disponibilizam os artigos na integra, decidiu-se mapear os locais, datas e o idioma de publicação dos textos, buscando-se uma visão geral da produção científica (Figura 1).

Observa-se que existem produções sobre saúde Penitenciária nos cinco Continentes. Contudo, verifica-se predominância do continente Americano e Europeu, destacando-se, naquele, os Estados Unidos da América (EUA), com 629 estudos; e, neste, a Inglaterra, com 253 trabalhos.

Estima-se que a população mundial encarcerada esteja em torno de 9,8 milhões de presos, sendo que metade destes está nos Estados Unidos da América (2,29 milhões), China (1,57 milhões) e Rússia (0,89 milhão). Os Estados Unidos possuem a maior taxa de população prisional no mundo (756 presos por 100 mil habitantes $)^{6}$.

Vale ressaltar que, da produção científica encontrada na Medline, 93\% estão publicadas em Inglês, idioma considerado pelos países hegemônicos como a língua universal. As de veiculação na Lilacs foram divulgados em Português $(89,5 \%)$ e Espanhol (10,5\%). A predominância desses idiomas deve-se ao fato de a Lilacs ser uma base de dados para divulgação de artigos dos países Latino-Americanos.

Destaca-se que a produção sobre a temática em tela na Figura 1, não era expressiva até a década de 1990. No cenário mundial, apenas a Inglaterra apresentava publicações (total de 18) e Estados Unidos, com 33 trabalhos, de 1975 até 1993.

Houve crescente aumento de trabalhos publicados da década de 1990, para a de 2000, com destaque especial para os anos de 2005, 2007, 2008 e 2009 , com 105, 112, 113 e 132 publicações, respectivamente.

Tal acontecimento coaduna-se com a preocupação da OMS com as questões da saúde nas prisões, culminando na criação do Projeto de Saúde no Sistema Prisional em 1995. Em 2003, o mesmo projeto publicou a Declaração de Moscou Sobre a Saúde Prisional, como parte da saúde pública.

Dos 1160 estudos que passaram pelo Teste de Relevância Preliminar, foram excluídos os que não se adequaram aos critérios de inclusão; restando, portanto, 23 artigos disponibilizados na íntegra. Essa etapa foi realizada por um dos pesquisadores, o qual já tinha vem se dedicando ao estudo do tema e apresenta experiência em revisão sistemática, contudo tal conduta não elimina o viés de outro pesquisador considerar relevante a inclusão ou exclusão de artigos diferenciados dos que foram selecionados para esse estudo. Com esse entendimento, passou-se para o Teste de Relevância II. Neste, dos 23 artigos selecionados no Teste Preliminar foram excluídos oito por serem repetidos; dois, por não serem revisões; um, por ser tese, a qual tem como fruto um artigo já incluso na pesquisa; e um por se tratar de editorial; restaram, então, 11 artigos que foram direcionados para o Teste de Relevância Final.

\section{Descrição e análise dos artigos}

Após o Teste de Relevância Final, todos os onze artigos analisados foram considerados adequados para a pesquisa, compondo então a amostra do estudo (Quadro 1). Ainda, dando continuidade à apresentação dos artigos, foram extraídos dos textos analisados os seguintes dados: objetivos, população estudada e resultados encontrados (Quadro 2).

Diante do que foi encontrado, evidencia-se que a produção científica pesquisada é bastante recente, estando a primeira publicação datada de 2002, com um artigo. Nos anos subsequentes, tem-se: 2003 (um artigo), 2004 (um artigo), 2006 


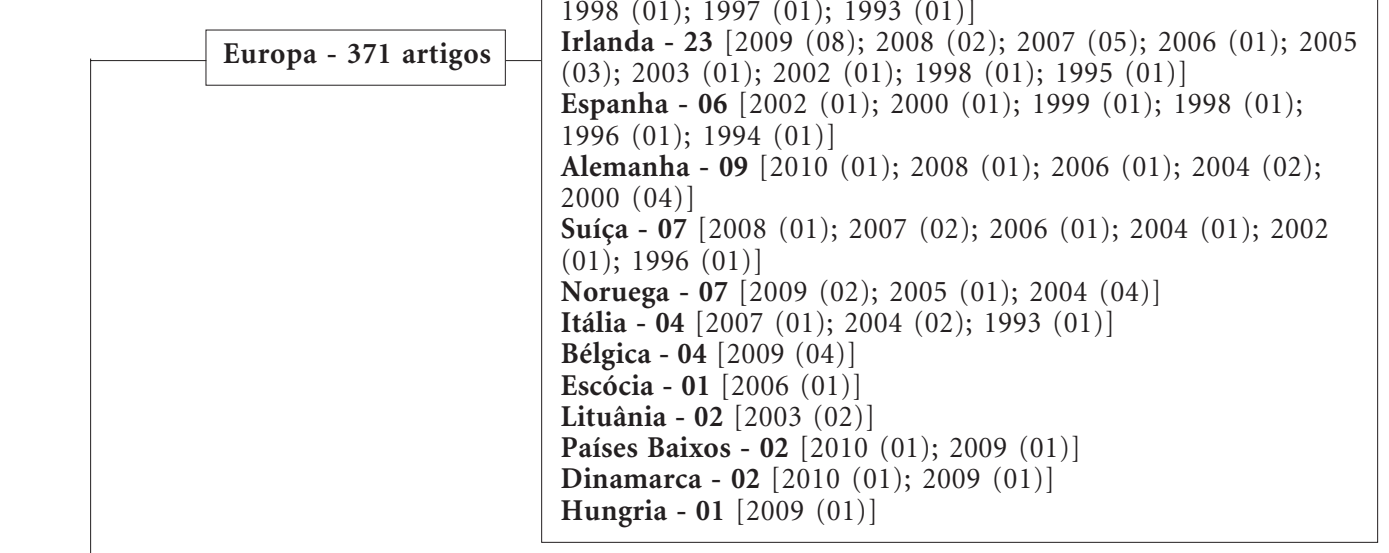

Inglaterra - 253 [2010 (04); 2009 (11); 2008 (55); 2007 (39) 2006 (29); 2005 (18); 2004 (11); 2003 (24); 2002 (08); 2001 (24); 2000 (07); 1999 (10); 1998 (05); 1997 (01); 1996 (07); 1995 (05); 1994 (01); 1993 (04)]

Holanda - 24 [2010 (02); 2009 (12); 2008 (03); 2007 (03); 2006 (01); 2004 (02); $1999(01)]$

França - 27 [2010 (01); 2009 (02); 2008 (02); 2005 (04); 2004 (03); 2003 (03); 2002 (03); 2001 (02); 2000 (01); 1999 (03); $1998(01) ; 1997$ (01); $1993(01)]$ (03); 2003 (01); 2002 (01); 1998 (01); 1995 (01) $1996(01) ; 1994(01)]$

Alemanha - 09 [2010 (01); 2008 (01); 2006 (01); 2004 (02); $2000(04)]$

$(01) ; 1996(01)]$

Noruega - 07 [2009 (02); 2005 (01); 2004 (04)

$004(02) ; 1993(01)$

Dinamarca - 02 [2010 (01); $2009(01)]$

Hungria - $01[2009(01)]$

América - 659 artigo

Estados Unidos - 629 [2010 (01); 2009 (82); 2008 (38); 2007 (55); 2006 (50); 2005 (66); 2004 (39); 2003 (31); 2002 (62); 2001 (39); 2000 (26); 1999 (34); 1998 (13); 1997 (20); 1996 (18); 1995 (14); 1994 (26); 1993 (15)]

Canadá - 30 [2009 (05); 2008 (03); 2007 (02); 2005 (01); 2004 (05); 2003 (03); 2000 (03); 1999 (02); 1998 (02); 1997 (02); $1996(01) ; 1995(01)]$

\section{MEDLINE Japão - 03 [2009 (03)]}

Rússia - 12 [2008 (02); 2007 (03); 2005 (01); 2004 (03); 2003 (02); $2001(01)]$

Índia - 02 [1995 (02)]

Coréia - 01 [1997(01)]

Malásia - 01 [2003 (01)]

Líbano - 02 [2001 (02)]

Tailândia - 01 [2001 (01)]

Indonésia - 01 [2008 (01)]

África do Sul - 02 [2005 (01); 1999 (01)

Egito - 08 [2009 (02); 2008 (01); 2007 (02); 2003 (01); 2002 (02)]

Quênia - 02 [2006 (02)]

Nigéria - 02 [2009 (01); $2001(01)]$

Madagascar - 01 [1995 (01)]

Austrália - 34 [2009 (02); 2008 (06); 2007 (02); 2006 (01); 2005 (08); 2004 (06); 2003 (03); 1999 (01); 1997 (04); 1998 (01)] Nova Zelândia - 02 [2002(02)]

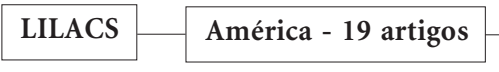

Brasil - 17 [2009 (01); 2006 (03); 2005 (03); 2004 (01); 2003 (02) 2002 (01); 2001 (02); 1999 (02); 1998 (01); 1997 (01)]

Nicarágua - 01 [1998 (01)]

Chile - 01 [2008 (01)]

Figura 1. Distribuição geográfica dos artigos encontrados nas bases de dados MEDLINE e LILACS, no período entre 1993 a 2010 
Quadro 1. Relação dos artigos publicados na Scielo sobre Saúde Penitenciária

\begin{tabular}{|c|c|c|c|c|}
\hline Autoria/ano & $\begin{array}{l}\text { Categoria dos } \\
\text { artigos }\end{array}$ & Método & Cenário do estudo & $\begin{array}{l}\text { Periódico de } \\
\text { Publicação }\end{array}$ \\
\hline Coelho et al. ${ }^{9}$ & Original & Quantitativo & $\begin{array}{l}\text { Penitenciária masculina, Ribeirão } \\
\text { Preto - SP, Brasil }\end{array}$ & $\begin{array}{l}\text { Revista Brasileira de } \\
\text { Epidemiologia }\end{array}$ \\
\hline Coelho $^{10}$ & Original & Qualitativo & $\begin{array}{l}\text { Penitenciária Masculina. } \\
\text { Salvador - BA, Brasil }\end{array}$ & $\begin{array}{l}\text { Ciência \& Saúde } \\
\text { Coletiva }\end{array}$ \\
\hline $\begin{array}{l}\text { Nogueira e } \\
\text { Abrahao }^{11}\end{array}$ & Original & Quantitativo & $\begin{array}{l}9 \text { Distritos Poli-ciais da Zona Oeste } \\
\text { da cidade de São Paulo - SP, Brasil. }\end{array}$ & $\begin{array}{l}\text { Revista Brasileira de } \\
\text { Epidemiologia }\end{array}$ \\
\hline Gabe e Lara ${ }^{12}$ & Original & Quantitativo & $\begin{array}{l}\text { Penitenciária Feminina. Porto } \\
\text { Alegre - RS, Brasil }\end{array}$ & $\begin{array}{l}\text { Revista Brasileira de } \\
\text { Análises Clínicas }\end{array}$ \\
\hline Sánchez et al. ${ }^{13}$ & Original & Quantitativo & $\begin{array}{l}\text { Penitenciária Masculina. Rio } \\
\text { de Janeiro - RJ, Brasil }\end{array}$ & $\begin{array}{l}\text { Cadernos de Saúde } \\
\text { Pública }\end{array}$ \\
\hline Akeke et al. ${ }^{14}$ & Original & Quantitativo & $\begin{array}{l}\text { Quthing Prisão - Quthing, } \\
\text { Lesoto }\end{array}$ & $\begin{array}{l}\text { West Indian Medical } \\
\text { Journal }\end{array}$ \\
\hline Strazza et al. ${ }^{15}$ & Original & Quantitativo & $\begin{array}{l}\text { Penitenciária Feminina Modelo. } \\
\text { São Paulo - SP, Brasil }\end{array}$ & $\begin{array}{l}\text { Cadernos de Saúde } \\
\text { Pública }\end{array}$ \\
\hline Carvalho et al. ${ }^{16}$ & Original & Quantitativo & $\begin{array}{l}\text { Sistema Penitenciário do Rio } \\
\text { de Janeiro - RJ, Brasil }\end{array}$ & $\begin{array}{l}\text { Ciência \& Saúde } \\
\text { Coletiva }\end{array}$ \\
\hline Miranda et al. ${ }^{17}$ & Original & Quantitativo & $\begin{array}{l}\text { Penitenciária Feminina. } \\
\text { Cariacica - ES, Brasil }\end{array}$ & Revista Saúde Pública \\
\hline Cravioto et al. ${ }^{18}$ & Original & Quantitativo & $\begin{array}{l}\text { Penitenciária Juarez, Chihuahua, } \\
\text { México }\end{array}$ & $\begin{array}{l}\text { Salud Pública de } \\
\text { México }\end{array}$ \\
\hline Peres et al. ${ }^{19}$ & Original & Quanti-Qualitativa & $\begin{array}{l}\text { Um centro de internação da Fundação } \\
\text { Estadual do Bem Estar do Menor } \\
\text { (Febem). São Paulo - SP, Brasil }\end{array}$ & Revista Saúde Pública \\
\hline
\end{tabular}

(um artigo), 2007 (três artigos), 2008 (um artigo) e 2009 (três artigos).

Observando-se a área de conhecimento dos periódicos, percebe-se que as publicações estão veiculadas em revistas cujo enfoque é a Saúde Pública, na seguinte ordem: Caderno de Saúde Pública, Ciência \& Saúde Coletiva, Revista Brasileira de Epidemiologia e Revista Saúde Pública (dois artigos cada), Revista Brasileira de Análises Clínicas, West Indian Medical Journal e Salude Publica de México (um artigo cada).

Nesta revisão, também foi possível constatar que os artigos analisados possuem ao todo 45 autores. Em relação a esses pesquisadores, podese montar o perfil em relação à profissão e titulação, onde se encontrou apenas os dados de 31 pesquisadores. Em relação à profissão, localizouse os seguintes dados: 15 médicos/as, 06 psicólogos/as, 3 enfermeiros/as, 2 matemáticos/as, 1 bióloga, 1 biomédica, 1 administrador, 1 antropóloga e 1 físico. No que diz respeito à titulação, estão disponibilizados os seguintes dados: 5 Pósdoutores, 16 Doutores, 8 Mestres e 1 Licenciado.

Em função do conteúdo dos artigos originais analisados - frutos dos resultados de estudos empíricos, experimental ou conceitual sobre o assunto em pauta - observa-se a predominância de pesquisas com abordagem quantitativa. Uma possível explicação pode ser o fato da maioria desses estudos terem como objetivo predominante a identificação de incidência e de prevalência de doenças como tuberculose, hepatite B e C, 
Quadro 2. Descrição dos artigos publicados na Scielo sobre Saúde Penitenciária

\begin{tabular}{|c|c|c|c|}
\hline Autoria /ano & $\begin{array}{l}\text { População } \\
\text { estudada }\end{array}$ & Objetivos & Resultados encontrados \\
\hline Coelho et al. ${ }^{9}$ & $\begin{array}{l}333 \text { presidiários, do } \\
\text { sexo masculino }\end{array}$ & $\begin{array}{l}\text { Estimar a prevalên-cia do Vírus da } \\
\text { Hepatite B (HBV) e seus fatores de } \\
\text { risco na população masculina } \\
\text { carcerária. }\end{array}$ & $\begin{array}{l}\text { A prevalência de infecção pelo HBV foi de } \\
\text { 19,5\% e esteve as-sociada à idade acima de } 30 \\
\text { anos, uso prévio de drogas injetáveis e } \\
\text { compartilhamento de agulhas prévio. }\end{array}$ \\
\hline Coelho ${ }^{10}$ & $\begin{array}{l}28 \text { presidiários } \\
\text { presos, do sexo } \\
\text { masculino }\end{array}$ & $\begin{array}{l}\text { Investigar os signos, significados e } \\
\text { práticas relacionados à normalidade e } \\
\text { à saúde mental por infratores presos. }\end{array}$ & $\begin{array}{l}\text { Ao mesmo tempo em que eles consideraram a } \\
\text { violência como característico de uma } \\
\text { anormalidade ou doença, não se consideraram } \\
\text { nem anormais nem violentos. }\end{array}$ \\
\hline $\begin{array}{l}\text { Nogueira e } \\
\text { Abrahao }^{11}\end{array}$ & $\begin{array}{l}1.052 \text { presos, sexo } \\
\text { masculino }\end{array}$ & $\begin{array}{l}\text { Verificar a associação entre o tempo } \\
\text { de prisão e a taxa de infecção } \\
\text { tuberculosa na população carcerária. }\end{array}$ & $\begin{array}{l}\text { Quanto maior o tempo de prisão, maior a } \\
\text { taxa de infecção tuberculosa. Detentos } \\
\text { reincidentes são um risco de infecção para os } \\
\text { detentos primários. }\end{array}$ \\
\hline Gabe e Lara ${ }^{12}$ & $\begin{array}{l}76 \text { presidiárias, sexo } \\
\text { feminino }\end{array}$ & $\begin{array}{l}\text { Determinar a prevalência de anti- } \\
\text { HCV (vírus da hepatite C), anti-HIV e } \\
\text { coinfecção HCV/HIV em um presídio } \\
\text { feminino. }\end{array}$ & $\begin{array}{l}\text { 14,47\% das amostras sorológicas foram } \\
\text { positivaspara HCV, } 9,21 \% \text { para HIV e } 2,63 \% \\
\text { para coinfecção HCV/HIV. }\end{array}$ \\
\hline $\begin{array}{l}\text { Sánchez et } \\
\text { al. }{ }^{13}\end{array}$ & $\begin{array}{l}3014 \text { presos, sexo } \\
\text { masculino (Prisão } \\
\text { A: } 1052 \text {; Prisão B: } \\
\text { 590; Prisão C: } 1372 \text { ) }\end{array}$ & $\begin{array}{l}\text { Comparar a prevalência de } \\
\text { tuberculose (TB), e as características } \\
\text { sócio-demográficas e epidemiológicas } \\
\text { dos internos de diferentes unidades } \\
\text { prisionais. }\end{array}$ & $\begin{array}{l}\text { Os indivíduos encarcerados oriundos de } \\
\text { comunidades desfavorecidas possuem maior } \\
\text { prevalência de TB. }\end{array}$ \\
\hline Akeke et al. ${ }^{14}$ & $\begin{array}{l}123 \text { presos, do sexo } \\
\text { masculino }\end{array}$ & $\begin{array}{l}\text { Avaliar o conhecimento e atitudes em } \\
\text { relação ao HIV/AIDS entre os presos. }\end{array}$ & $\begin{array}{l}95,5 \% \text { dos reclusos sabiam a causa da AIDS e } \\
70 \% \text { dos presos sabiam como a mesma } \\
\text { poderia ser transmitida, porém, } 41,5 \% \text { não } \\
\text { usavam preservativos. }\end{array}$ \\
\hline Strazza et al. ${ }^{15}$ & $\begin{array}{l}290 \text { presidiárias, } \\
\text { sexo feminino }\end{array}$ & $\begin{array}{l}\text { Estudar aspectos relacionados ao } \\
\text { comportamento sexual e associados } \\
\text { ao risco de transmissão do Vírus da } \\
\text { Imunodeficiência Humana (HIV) e } \\
\text { da hepatite } \mathrm{C} \text { em detentas. }\end{array}$ & $\begin{array}{l}\text { O risco parenteral foi associado com infecções } \\
\text { pelo HIV e HCV, e o sexual, pelo HIV. }\end{array}$ \\
\hline $\begin{array}{l}\text { Carvalho de } \\
\text { et al. }{ }^{16}\end{array}$ & 2.039 detentos & $\begin{array}{l}\text { Conhecer o perfil da população } \\
\text { encarcerada, identificando se o fator } \\
\text { da exclusão social difere quanto ao } \\
\text { sexo. }\end{array}$ & $\begin{array}{l}\text { Fatores associados ao sexo masculino: visita } \\
\text { íntima na prisão, ser casado, condenação por } \\
\text { roubo; para o sexo feminino: DST, ser viúva, } \\
\text { estrangeira e ter } 35 \text { anos ou mais. }\end{array}$ \\
\hline $\begin{array}{l}\text { Miranda et } \\
\text { al. }{ }^{17}\end{array}$ & $\begin{array}{l}121 \text { mulheres com } \\
\text { idade superior a } 18 \\
\text { anos }\end{array}$ & $\begin{array}{l}\text { Identificar o perfil sociodemográfico e } \\
\text { as condições de saúde das mulheres } \\
\text { encarceradas. }\end{array}$ & $\begin{array}{l}\text { Todas as detentas já haviam tido atividade } \\
\text { sexual pregressa e } 28 \% \text { apresentavam história } \\
\text { de DST. }\end{array}$ \\
\hline $\begin{array}{l}\text { Cravioto et } \\
\text { al. }{ }^{18}\end{array}$ & $\begin{array}{l}1208 \text { detentos do } \\
\text { sexo masculino e } \\
\text { feminino com idade } \\
\text { superior a } 18 \text { anos }\end{array}$ & $\begin{array}{l}\text { Descrever a prevalência do uso de } \\
\text { heroína e identificar as barreiras de } \\
\text { acesso ao tratamento. }\end{array}$ & $\begin{array}{l}\text { A prevalência de consumo de heroína foi de } \\
26,4 \% \text {. As barreiras de acesso ao tratamento } \\
\text { foram: baixa escolaridade, superdosagem, } \\
\text { presença de doenças crônicas. }\end{array}$ \\
\hline Peres et al. ${ }^{19}$ & $\begin{array}{l}275 \text { jovens internos, } \\
\text { do sexo masculino }\end{array}$ & $\begin{array}{l}\text { Descrever o perfil de adolescentes } \\
\text { detentos quanto ao apoio social e } \\
\text { familiar, ao uso de drogas e } \\
\text { conhecimentos, práticas e atitudes } \\
\text { relacionadas à AIDS e sua prevenção. }\end{array}$ & $\begin{array}{l}90 \% \text { dos jovens internos residiam com suas } \\
\text { famílias antes da internação. Acreditam que o } \\
\text { preservativo é frágil ( } 83 \%) \text {; e } 9 \% \text { relatam o } \\
\text { uso frequente. }\end{array}$ \\
\hline
\end{tabular}


Síndrome da Imunodeficiência Adquirida (SIDA) e caracterização do perfil sociodemográfico da população encarcerada.

Os métodos quantitativos permitem avaliar a importância, a gravidade, o risco, a tendência de agravos e as ameaças, através de associações estatísticas que possibilitam retratar aspectos de uma realidade. Contudo, o campo da saúde é produto de uma realidade complexa que envolve aspectos biológicos, físicos, psicológicos, sociais e ambientais, havendo também a necessidade de se avaliar valores, crenças e atitudes dos grupos a quem as ações se dirigem, o que demanda investigações com abordagem qualitativa.

\section{Cenários estudados}

Os grandes centros - São Paulo e Rio de Janeiro - foram os focos de diversos estudos acerca das penitenciárias e da população que ali se encontra, totalizando 04 e 02 artigos, respectivamente $e^{9,11,13,15,16,19}$.

Segundo o Ministério da Justiça ${ }^{20}$, o Estado de São Paulo abrigava em 1997, 39\% da população carcerária do país. O número total de presos no Estado era de 67.786 mil, sendo que o sistema prisional oferecia apenas 24.222 mil vagas. Segundo o Departamento Penitenciário Nacional, o número total de presos do Estado aumentou para 153.056 mil em 2007, e as vagas disponíveis para 95.585 mil; entretanto o déficit de vagas aumentou para 57.471 mil.

Conforme um dos estudos ${ }^{13}$, o Sistema Penitenciário do Estado do Rio de Janeiro abrigava, em 2004, cerca de 21 mil presos distribuídos em 34 unidades prisionais (média de 558 indivíduos por unidade), em celas superpopulosas e mal ventiladas, condições essas favoráveis à transmissão de diversas doenças infecciosas. Outros pesquisadores afirmam que o estado do Rio de Janeiro, além de estar acima da média nacional nas taxas de crimes letais intencionais, teve a taxa crescendo $14 \%$ no período compreendido entre o primeiro semestre de 2001 e o primeiro semestre de $2003^{16}$.

Em relação à incidência de registros de crimes violentos não letais contra a pessoa, verifica-se que seis Unidades da Federação possuem taxas superiores à média nacional, estando entre eles, São Paulo e Rio de Janeiro. Todos os Estados da Região Sudeste apresentaram taxas de crimes violentos contra o patrimônio que cresceram no mesmo período, no qual São Paulo e Rio de Janeiro encontram-se acima da média analisada ${ }^{2}$.

Peres ${ }^{19}$ entende que a questão da criminalidade vem sendo utilizada como instrumento de acesso para garotos pobres conseguirem cidadania: ganhar dinheiro, fazer parte de um grupo de referência, desenvolver identidade masculina, testar limites e conseguir respeito.

Além desses fatores extramuros que levam à busca pela identificação da situação criminal e de confinamento dos presos, há a notória precariedade observada intramuros dos grandes centros penitenciários.

\section{População estudada quanto ao Sexo}

Identificou-se uma predominância de estudos realizados com detentos do sexo masculino, em comparação ao sexo feminino, fato que vem em conformidade com a predominância da população carcerária ser majoritariamente do sexo masculino ${ }^{13}$. Leva-se em conta também que o grupo masculino é o mais envolvido em situações de violência, e com maior o índice de reincidência em crimes e, consequentemente, no cumprimento de pena prisional ${ }^{16}$.

Estudo realizado mostra que embora homens e mulheres encarcerados sejam igualmente excluídos da "vida social" antes e depois da prisão, existem algumas características que os diferenciam nesse processo de exclusão. Os fatores carcerários mais fortemente associados ao sexo masculino são: visita íntima na prisão, estar preso por sete anos ou mais, ser casado, condenação por roubo, ter ainda três anos ou mais a cumprir de pena e uso de maconha antes de ser preso; enquanto os associados ao sexo feminino dizem respeito a: doença sexualmente transmissível, ser viúva, estrangeira, usar tranquilizante na prisão, ter visitado alguém na prisão antes de ser presa e ter 35 anos ou mais ${ }^{16}$.

Diante desta problemática, surgem algumas questões de saúde e necessidades específicas de cada sexo, principalmente se tratando de pessoas que vivem em confinamento. $\mathrm{O}$ foco das pesquisas realizadas com homens presidiários foi voltado para a SIDA, a tuberculose, a infecção pelo Vírus da Hepatite B (VHB) e a saúde mental.

Akeke et al. ${ }^{14}$ buscaram avaliar os conhecimentos e as atitudes sobre SIDA entre os detentos, e quais os desafios na prevenção desta doença, pois, segundo os autores, há escassez de aconselhamento e apoio aos prisioneiros que vivem com a doença. O mesmo estudo verificou que o conhecimento sobre a questão era elevado, apesar dos equívocos sobre a patologia e o uso do preservativo, sendo necessárias intervenções aos presos através de educação nas prisões.

Corroborando a afirmativa supracitada, outro estudo identificou que os presos apresentam elevado risco de contaminação com o Vírus da 
Imunodeficiência Humana (HIV), dentre vários fatores, incluindo a não importância dada ao uso do preservativo ${ }^{16}$.

A SIDA é, ainda, o fator de risco mais importante para a progressão da tuberculose, que possui ainda outros fatores associados para sua disseminação nas prisões, como: superlotação, a pouca ventilação, condições sanitárias adversas, baixo nível socioeconômico e uso de drogas ${ }^{13}$.

Quanto à problemática da infecção pelo vírus da hepatite $\mathrm{B}$, foi estimada a prevalência do marcador e seus fatores de risco na população masculina, verificando a necessidade de programas preventivos voltados a essa população?

Já em relação à investigação abordando mulheres presidiárias, a infecção pelo HIV e pelo Vírus da Hepatite C (HCV) e a saúde sexual e reprodutiva foram os focos mais abordados.

O Comitê Internacional da Cruz Vermelha considera importante tais enfoques, visto que as mulheres têm necessidades de saúde específicas, principalmente com relação à saúde reprodutiva. Além de serem vulneráveis à violência sexual, aumentando o risco de gravidez indesejada, infecção com Vírus da Imunodeficiência Humana (HIV) e outras doenças sexualmente transmissíveis $(\mathrm{DST})^{21}$.

O último relatório da Organização Mundial de Saúde (OMS) afirma ainda que o uso de drogas e a infecção com HIV é maior entre as internas do que entre presos do sexo masculino ${ }^{6}$.

A maior ocorrência de DST entre as mulheres pode estar associada ao fato de elas buscarem mais os serviços de saúde para diagnóstico e tratamento, além da cronicidade dessas doenças entre a população do sexo feminino ${ }^{16}$. Outra pesquisa enfatiza relevante associação entre o uso de drogas injetáveis dentre essa população e a crescente incidência da Síndrome da Imunodeficiência Adquirida (AIDS) no sexo feminino ${ }^{15}$.

Nessa mesma perspectiva, estudos revelam que as condições em que se encontra a população feminina encarcerada as predispõe a vulnerabilidade tanto à infecção pelo HIV, quanto pelo $\mathrm{HCV}$, pois os dois tipos de doenças possuem semelhantes modos de transmissão ${ }^{12,15}$.

\section{Principais temáticas abordadas}

Os artigos analisados tiveram por objetivos, na sua maioria, a identificação do perfil sociodemográfico e das condições de saúde dos encarcerados; seguidos pelo estudo da incidência de tuberculose, infecção pelo HIV/AIDS e HCV nos presídios.
O estudo da situação sociodemográfica nos permite conhecer diferentes características da população prisional, associando às patologias, às formas de prevenção e ao tratamento das mesmas.

Nesse sentido, pesquisadores identificaram que o perfil de exclusão social a que essa população é submetida difere quanto ao sexo, à idade, ao estado civil, ao tempo de encarceramento e à nacionalidade ${ }^{16}$.

Identificou-se, então, que a população carcerária é predominantemente jovem: média de 28 anos para os homens e 31 anos para as mulheres. A proporção de estrangeiros foi cinco vezes maior em mulheres do que em homens, sendo elevado o número de presos que tinham história de passagem pelo Juizado da Infância e da Juventude. A maior parte das mulheres havia sido condenada devido ao tráfico de drogas, enquanto os homens, por motivo de furto. Em relação, ainda, ao perfil da população em questão, os estudos apontam que mulheres encarceradas possuem, na grande maioria, baixo nível socioeconômico e educacional, alto índice de DST, com história de uso de alguma droga ilícita e álcool, e não utilização da camisinha durante as relações sexuais.

No tocante aos dados sociodemográficos dos presos do sexo masculino, autores afirmam que a maioria dos participantes em seu estudo se definiu como sendo branco. Quanto à escolaridade, todos haviam estudado em escola pública, sendo que mais da metade interrompeu os estudos antes do encarceramento. Em geral, os jovens acreditam possuir baixa expectativa de vida por conta da violência e quase metade havia sido interno na Fundação Estadual do Bem-Estar do Menor (FEBEM), sendo $80 \%$ dos casos por motivos de assaltos e furtos. A droga constatada com mais uso entre os presos é a maconha; e no tocante à sexualidade, a maioria dos detentos já praticou atividade sexual sem utilização do preservativo e considera este método frágil ou dispensável ${ }^{19}$.

Além disso, as precárias condições de confinamento, a desnutrição, a superlotação das celas, a marginalização social, a dependência de drogas ilícitas e o baixo nível socioeconômico são fatores que facilitam a elevada disseminação de doenças e agravos entre presidiários, como tuberculose, hepatite $B$, hepatite C, AIDS e outras doenças sexualmente transmissíveis.

Estudo realizado por Nogueira e Abrahao ${ }^{11}$, concluiu que, além das precárias condições de higiene, a baixa qualidade de alimentação e o stress causado pela situação de confinamento aumentam o risco de adoecimento dos presos. $\mathrm{O}$ 
tempo de prisão também está diretamente relacionado à alta taxa de infecção tuberculosa; representando assim, uma ameaça à saúde pública e ao controle dessa endemia.

Pesquisas analisaram a prevalência e o comportamento associado à infecção pelo HIV e pelo $\mathrm{HCV}$, pois ambas compartilham semelhantes modos de transmissão, sendo por via parenteral, sexual e/ou vertical. As prevalências de infecção para o HIV e o HCV no primeiro estudo foram de 2,6\% e $9,2 \%$, respectivamente; e no segundo de $13,9 \%$ e $16,2 \%$, respectivamente, sugerindo que os dados seguem uma distribuição semelhante ${ }^{12,15}$.

Ressalta-se, ainda, através dos estudos supracitados que a população encarcerada é vulnerável à transmissão parenteral de HCV e HIV, considerado o principal meio, através do uso de drogas injetáveis e pela transmissão via práticas sexuais de risco, além de associarem esse quadro às condições de confinamento e ao status social marginalizado.

Muito frequentemente, encontram-se visões reducionistas e relações diretas ligando drogas e crime, sem uma análise mais aprofundada da complexidade da questão. As populações encarceradas são formadas, em grande parte, por usuários de drogas. Assim sendo, os delitos associados ao uso ou ao tráfico de drogas ilícitas representam mais de $50 \%$ dos motivos de encarceramento ${ }^{17}$.

Um dos estudos apresenta que a história de uso de drogas é bastante elevada dentro da prisão, correlacionada diretamente com o vício antes de serem presos. O uso do álcool é predominante antes do encarceramento. Na prisão, o uso da maconha predomina entre os homens e o uso de tranquilizantes entre as mulheres. Os homens utilizaram um número maior de combinação de drogas do que as mulheres. Ao se analisar os usos combinados de maconha e cocaína, 70\% dos homens informaram uso de pelo menos uma das drogas antes da prisão e $33 \%$ no confinamento ${ }^{16}$.

Tais resultados estão de acordo com os encontrados em prisões americanas, onde mais de $70 \%$ relatam história de uso de drogas nas prisões federais e mais de $80 \%$, nas prisões estaduais e locais $^{22}$. Dados do U.S. Department of Justi$\mathrm{ce}^{23}$ informam que mais da metade dos presos que cumprem pena por atos violentos contra esposas(os), namoradas(os), parceiras(os), considerando a relação atual ou não, têm história de uso de álcool, outras drogas ou ambos no momento do incidente que gerou a prisão.

Correlacionado à saúde, o uso de drogas pode trazer diversos agravos. Com esse enfoque, tem-se uma pesquisa que tem como resultado, descrito por presidiárias, o uso regular de álcool, maconha e cocaína. Considerado comportamento de risco para Doenças Sexualmente Transmissíveis (DST) e infecção pelo HIV, além de outras doenças crônicas e infecciosas de diversos graus de severidade e de complexidade em sua identificação e manejo clínico ${ }^{17}$.

Diante da amplitude de informações, os indicativos deste artigo apontam para a importância dos profissionais de saúde adquirirem informações acerca da temática explorada, a fim de formular estratégias voltadas à saúde da população encarcerada, contribuindo para uma melhor resolubilidade dos problemas associados à mesma.

\section{Conclusões}

Nota-se que a Saúde Penitenciária é um tema presente na discussão de ordem mundial, com um crescente aumento de trabalhos científicos publicados da década de 1990 para a de 2000, com predominância de pesquisas com abordagem quantitativa, evidenciando uma possível lacuna no enfoque qualitativo.

Os estudos tornam notável que a saúde dos detentos é uma problemática latente e um campo aberto e amplo a ser explorado, sendo uma questão de saúde pública, na qual a própria condição de confinamento dos detentos representa uma oportunidade singular para a implementação de programas terapêuticos, medidas preventivas e ações educativas específicas para esse segmento da população, que, em geral, tem menos acesso aos serviços de atenção à saúde.

Aponta-se a necessidade de produção de saberes específicos na área da saúde penitenciária, que visem subsidiar práticas que possam vir a se tornar estratégias, ferramentas e modelos teórico-práticos para o processo de cuidar diante das necessidades específicas dos encarcerados. 


\section{Colaboradores}

SM Gois, HPO Santos Junior, MFA Silveira e MMP Gaudêncio participaram igualmente de todas as etapas de elaboração do artigo.

\section{Referências}

1. Brasil. Centro de Documentação do Ministério da Saúde. $8^{a}$ Conferência Nacional de Saúde. Brasília: MS; 1986.

2. Brasil. Lei n. ${ }^{\circ} 7.210$ de 11 de julho de 1984. Institui a Lei de Execução Penal. Diário Oficial da União 1984; 13 jul.

3. Silva GKN, Vedovello VP, Fegadolli C. Políticas e práticas da assistência farmacêutica penitenciária. UNIMEP [periódico na Internet]. 2008 [acessado 2009 nov 11]: [cerca de 7 p.]. Disponível em: http:/ /www.unimep.br/phpg/mostraacademica/anais/ 4mostra/pdfs/489.pdf.

4. Brasil. Portaria Interministerial n. ${ }^{\circ} 1.777$, de 9 de setembro de 2003. Dispõe sobre o Plano Nacional de Saúde no Sistema Penitenciário. Brasília: Ministério da Saúde, Ministério da Justiça; 2003.

5. Brasil. Portaria n. ${ }^{\circ} 1.552 / \mathrm{GM}$ de 28 de julho de 2004 . Publica os valores do custeio do Plano Nacional de Saúde no Sistema Penitenciário, e dá outras providências. Diário Oficial da União 2004; 28 jul.

6. Walmsley R. World prison population list. International Centre for Prison Studies. World Health Organization [periódico na Internet]. 2008. [acessado 2010 jun 10]: [cerca de 6 p.]. Disponível em: http:/ /www.kcl.ac.uk/depsta/law/research/icps/downloads/wppl-8th_41.pdf.

7. World Health Organization. Health in prisons: a WHO guide to the essentials in prison health. Copenhagen: Organization Regional Office for Europe; 2007.

8. Galvão CM, Sawada NO, Trevizan MA. Revisão sistemática: recurso que proporciona a incorporação das evidências na prática da enfermagem. Rev Latino-Am Enfermagem 2004;12(3):549-556.

9. Coelho HC, Oliveira SAN, Miguel JC, Oliveira MLA, Figueiredo JFC, Perdoná GC, Passos ADC. Soroprevalência da infecção pelo vírus da Hepatite B em uma prisão brasileira. Rev Bras Epidemiol 2009; 12(2):124-131.

10. Coelho MTAD. Concepções de normalidade e saúde mental entre infratores presos de uma unidade prisional da cidade do Salvador. Cien Saude Colet 2009; 14(2):567-575.

11. Nogueira PA, Abrahao RMCM. A infecção tuberculosa e o tempo de prisão da população carcerária dos Distritos Policiais da zona oeste da cidade de São Paulo. Rev Bras Epidemiol 2009; 12(1):30-38.

12. Gabe C, Lara GM. Prevalência de anti-HCV, antiHIV e co-infecção HCV/HIV em um presídio feminino do Estado do Rio Grande do Sul. RBAC 2008; 40(2):87-89.

13. Sanchez AR, Massari V, Gerhardt G, Barreto AW, Cesconi V, Pires J, Espínola AB, Biondi E, Larouzé B, Camacho LAB. A tuberculose nas prisões do Rio de Janeiro, Brasil: uma urgência de saúde pública. Cad Saude Publica 2007(3):545-552.

14. Akeke VA, Mokgatle M, Oguntibeju OO. Assessment of knowledge and attitudes about HIV/AIDS among inmates of Quthing prison, Lesotho. West Indian Med J 2007; 56(1):48-54.

15. Strazza L, Massad E, Azevedo RS, Carvalho HB. Estudo de comportamento associado à infecção pelo HIV e HCV em detentas de um presídio de São Paulo, Brasil. Cad Saude Publica 2007; 23(1):197-205. 
16. Carvalho ML, Valente JG, Assis SG, Vasconcelos AGG. Perfil dos internos no sistema prisional do Rio de Janeiro: especificidades de gênero no processo de exclusão social. Cien Saude Colet 2006; 11(2):461-471.

17. Miranda AE, Mercon-de-Vargas PR, Viana MC. Saúde sexual e reprodutiva em penitenciária feminina, Espírito Santo, Brasil. Rev Saude Publica 2004; 38(2):255-260

18. Cravioto P, Medina-Mora ME, De La Rosa B, Galván F, Tapia-Conyer R. Patrones de consumo de heroína en una cárcel de la frontera norte de México: barreras de acceso a tratamiento. Salud Pública de México 2003; 45(3):181-190.

19. Peres CA, Paiva V, Silveira F, Peres RA, Hearst N. Prevenção da Aids com adolescentes encarcerados em São Paulo, SP. Rev Saude Publica 2002; 36(Supl. 4):76-81.

20. Brasil. Ministério da Justiça. Secretaria de Justiça. Departamento Penitenciário Nacional. Censo Penitenciário de 1997. Brasília: Ministério da Justiça; 1998.

21. Comitê Internacional da Cruz Vermelha. Saúde na prisão: cuidando das mulheres em um mundo masculino. [site na Internet] 2009 [acessado $2009 \mathrm{dez}$ 04]. Disponível em: http://www.icrc.org/web/por/ sitepor0.nsf/html/women-health-prison-interview020309.

22. Freudenberg N. Jails, prisons, and the health of urban populations: a review of the impact of the correctional system on community health. J Urban Health 2001; 78(2):214-235.

23. U.S. Department of Justice. Office of Justice Programs. Bureau of Justice Statistics. Trends in violence against intimates. [site na Internet] 2009 [acessado 2012 abr 6]. Disponível em: http://bjs.ojp. usdoj.gov/content/pub/ascii/ipv.txt

Artigo apresentado em 26/09/2010

Aprovado em 25/12/2010

Versão final apresentada em 10/01/2011 